\title{
LYMPHANGITIS AND PERILYMPHANGITIS OF THE LIVER IN THEIR RELATIONS TO THE INFLAMMA- TIONS OF THE ORGAN.
}

\author{
HORST OERTEL. \\ NEW YORK CITX.
}

[From the Russell Sage Institute of Pathology, New Tork City Hospital.]

The importance of the lymphatics in the inflammatory lesions of parenchymatous organs is well recognized. They are not only frequent carriers of infection, but in the absorption of inflammatory products their condition becomes a paramount issue in the ultimate fate of the organs.

We know that in pneumonia, for instance, the state of the lymphatics determines the resorption of the exudate and, therefore, the termination of the whole disease. Obliteration of the lymphatics by an acute lymphangitis and perilymphangitis retards the resolution until these paths have been cleared, and, if this does not take place, aids the termination into gangrene or abscess. Again, permanent destruction ef lymphatics, as in chronic essential emphysema and in senile atrophy of the lung, are grave factors against rapid removal of inflammatory exudates and are almost entirely responsible for the long-continued, irregular course often taken by inflammations of the lungs, as well as for their frequent fatal termination in persons who already have the above-mentioned diseases. The same considerations apply with equal force to other parenchymatous organs. In the liver, however, their importance as carriers of infection and as determining factors in the course and termination of inflammatory lesions has been less emphasized than in connection with other organs-certainly much less emphasized than the rôle of the bile ducts and blood ressels, especially the ressels of the portal circulation. It is erroneous, however, to believe that the lymphatics of the liver may be disregarded or viewed as of secondary importance, for they present very definite and important changes in the various inflammatory conditions of this organ.

I shall confine myself in this article to the condition of the lymphatics in the "acute," "subacute," and "chronic" inflammations. For their study we have had unusual opportunity in this laboratory during the last few years, and some interesting cases have already been described 
in their main featurres. ${ }^{1}$ These cases, of which I need not repeat the details here, as well as some other typical "acute" inflammations occurring in connection with general infections, "chronic" forms, given in cirrhosis of the liver, and finally some found in acute exacerbations of "chronic" cirrhosis, furnish the basis of these observations. I shall disregard for the present specific affections, like the infective granulomata, in their relation to the lymphatics of the liver, leaving them for future consideration.

The liver, as is well known, is supplied by a rich network of lymphatics which is derived from two sources. The first and most important set, as far as the parenchyma is concerned, is that which accompanies the portal vessels, the bile ducts, the hepatic artery and the hepatic vein. The second and superficial set forms an extensive network within the capsule, and communicates with the first by means of channels through Glisson's capsule. Whether lymph channels occur within the acini is still a disputed question. From the pathological standpoint both of these lymphatic systems of the liver appear to have at least some degree of independence, for severe affections may remain confined to one without involving the other. Perlaps the best illustrations of this distinction are found in cases of Curschmann's so-called "sugar-glazed" liver, which is a hyperplastic deforming perihepatitis, or in cases of Pit psendocirrhosis, or in cases of polyserositis or hyaloserositis. Common to all of these is an enormous productive inflammatory thickening of the serous coat of the liver with extensive involvement of the superficial lymphatics only. On the other hand, in my experience, it is very rare to find extensive lymphatic involvement of the superficial or capsular set in inflammations of the liver itself, but these show marked disease of all internal lymphatics of a type which I shall presently describe. The only exceptions are cases in which a complicating peritonitis affects the lymphatics of the capsule.

It follows, therefore; that as far as the fate of the liver itself is concerned the affections of the internal lymphaties are the paramount issue, and I shall confine myself to them.

First, then, with regard to the so-called acute and subacute (better, exudative and productive) inflammations. ${ }^{2}$ I shall consider these together on account of their close relationship and the similarity of the affections

1. Symmers, D.: Am. Jour. Medi. Sci., 1908, exxxv, No. 2.

2. I use these terms in Cohnheim's and Orth's sense: Cohnheim, Vorlesungen iiber allgemeine Pathologic, 1877, p. 281 ; also Orth's Lehrbuch der speziellen pathologischen Anatomie, Berlin, 1887, Preface p. 4. Others speak of proliferative instead of productive inflammations (Ziegler). 


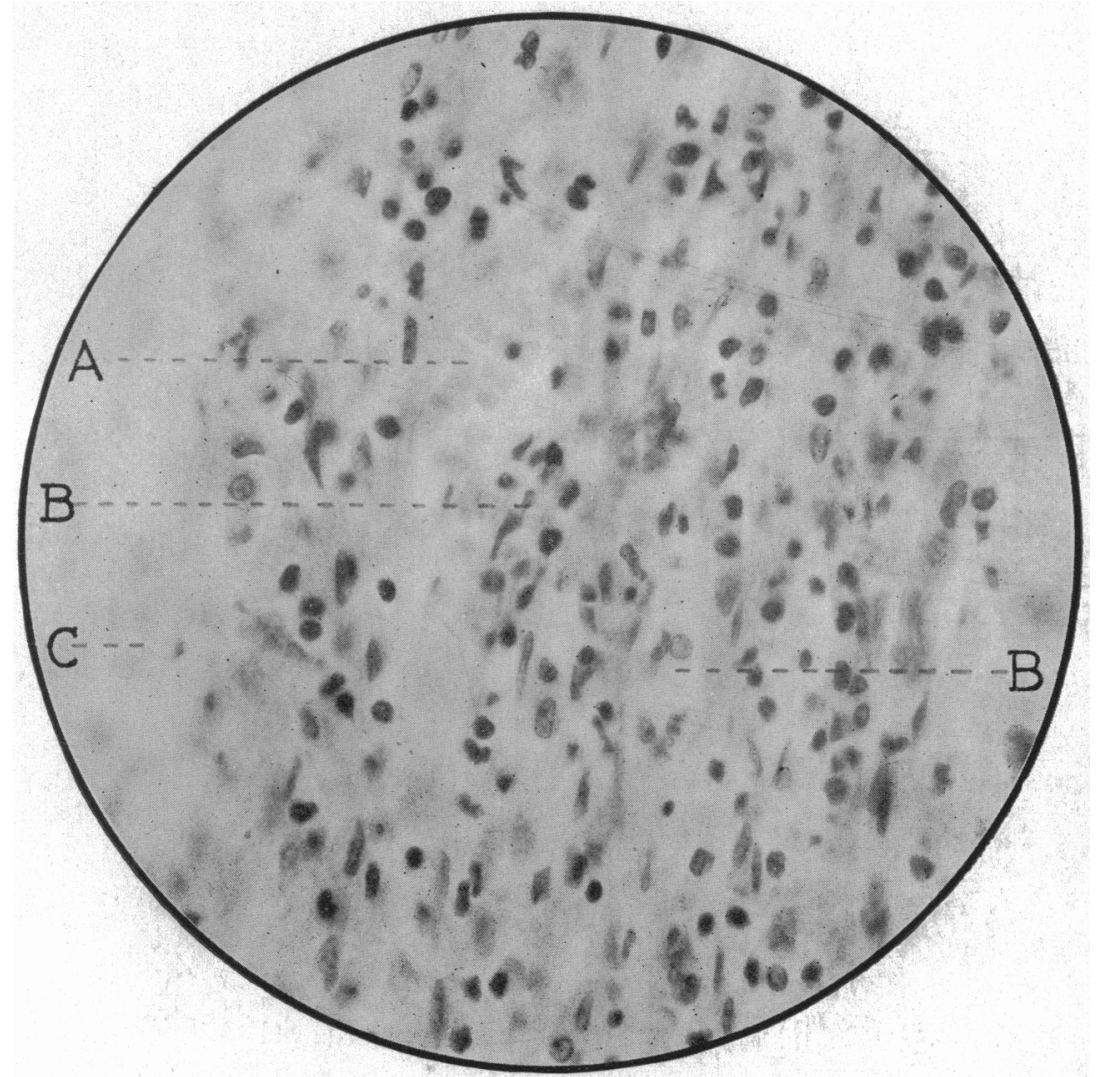

Fig. 1.-Exudative lymphangitis and perilymphangitis of a portal space (exudative interstitial inflammation of the liver); acute diffuse hepatitis. a. Blood vessel. $b$. Dilated lymph spaces filled with serum, leucocytes, mononuclear cells (desquamated endothelial cells.) $c$. Adjoining cloudy liver-cells. Zeiss: Oil immersion $2 \mathrm{~mm}$. Ocular $4 \mathrm{~mm}$.

Archives of INéreral Medicine.

Illustrating ARTicle by Horst OfRTel. 
of the lymphatics in the two. Changes occur here partly within and partly without the lymphatic channels of the interstitial tiasue between the lobules. The lymphaties are generally dilated with stagnant lymph; they are filled with coagulum and large and small mononuclear cells of the lymphoid type, desquamated endothelial cells and polymorphonuclear lencocytes (Fig. 1). In some cases this condition is well marked in the initial stages of the lesion, and it may form the central feature of the inflammatory affection of the interlobular septa-an acute lymphangitis. It may be immediately recognized by the regular streaky infiltrations of the interstices following exactly the line of the lymphatic courses. More frequently an involvement of the surrounding structures follow. As a result of the blocking of the lymph stream, the perilymphatic tissue becomes edematous (Fig. 1). This leads primarily to widening of the tissue spaces around the lymphatics, and the cellular infiltration with lymphocytic cells and polymorphonuclear leucocytes extends now to these structures. It may remain confined to the tissue spaces in the immediate neighborhood of the lymphatics, or it may, especially in advancing lesions, infiltrate more or less diffusely all the interstitial tissue. In other words, the lymphangitis becomes associated with a perilymphangitis.

The anatomic distribution of the lymphatic channels in the liver, which is mainly along the paths and in the sheaths of the vessels and the bile ducts, necessarily implicates them in all affections which take their origin from or around these latter structures. Even in these cases the lymphatic involvement, although secondary, becomes of great importance in the dissemination of the inflammation, for the lymphatics will not remain locally affected, but will carry infection to other distant parts of the liver substance. This factor reserves for the lymphatics a certain independence even in those cases in which they have become secondarily affected as the result of primary biliary and vascular infections. In other words, it is not necessary that the lymphangitis and perilymphangitis progress pari passu with the inflammation of the ducts and the vessels; nor does the severity of the lymphatic affection stand in a constant definite ratio to that of the bile ducts or the blood vessels. The active inflammatory process of the lymphatics necessarily modifies the extension and severity of the affection in each case. It has already been mentioned that we must attach to them an important rôle in the dissemination of a lesion. On the other hand, early and complete plugging of the lymphatics would form an aid for the localization of an infection. Further-and herein lies a very essential feature- 
all resorption of inflammatory products must be delayed or entirely suspended in areas thus affected, as long as the lymphatic circulation is interfered with by blocking of lymphatic and perilymphatic spaces. Whether, then, the liver is restored to its former integrity, or whether inflammatory changes will continue to spread or become permanent, depends largely on the status of the lymphatics. In order to have restitution to integrity it becomes necessary here, as in other parenchymatous organs, to have clear lymphatics. Although a morphological control is not possible, there can be no doulst that this occurs in a large number of cases in which the liver is "acutely" affected, but in a number of others, and they are the ones going on to productive inflammation and to true cirrhosis, restitution and clearing of lymphatics does not take place. but they show changes which, while they are not of the same exudative type as those previously described, are just as definite and important in their relation to the ultinate outcome of the disease. In these delared cases of restitution, in which the progress of the disease is manifest, the changes in the lymphatics are especially characterized by endothelial proliferation of their walls. This endothelial proliferation leads not only to thickening of the wall, but gradually to obstruction of the lumen of these vessels, for cndothelial cells gradually accumulate within the channel and sooner or later the lumen is entirely closed. This obliteration is considerably aided by free fibroblastic proliferation from without, which further tends to compress these lymphatic channels. The occlusion of these interstitial lymphatics goes, then, hand in hand with the formation of maturing fibrous connective tissue (Fig. 2). An interesting feature in this connection is the formation of new lymph channels along with new capillaries. Undoubtedly they serve here the same compensatory purpose that the newly-formed capillaries do, but, unfortunately, a large number of these newly-formed lymphatics suffer the same fate that many of the newly-formed blood ressels do; they are gradually squeezed ont of existence in the maturing and growth of the increasing connective tissue.

These more slowly progressing changes in the lymphatics are no less important in the productive inflammations of the liver than they are in the exudative conditions. In the first place, it seems evident that a large number of cases that begin as exudative interstitial hepatitis are considerably aided in assuming an additional productive character or in becoming purely productive, by obliteration of the lymphatics; for this must necessarily interfere with the proper lymph stream and thereby with the proper nutriment of the parts, and thus with the resorption of the inflammatory products. As a consequence the parenchyma suffers severely. 


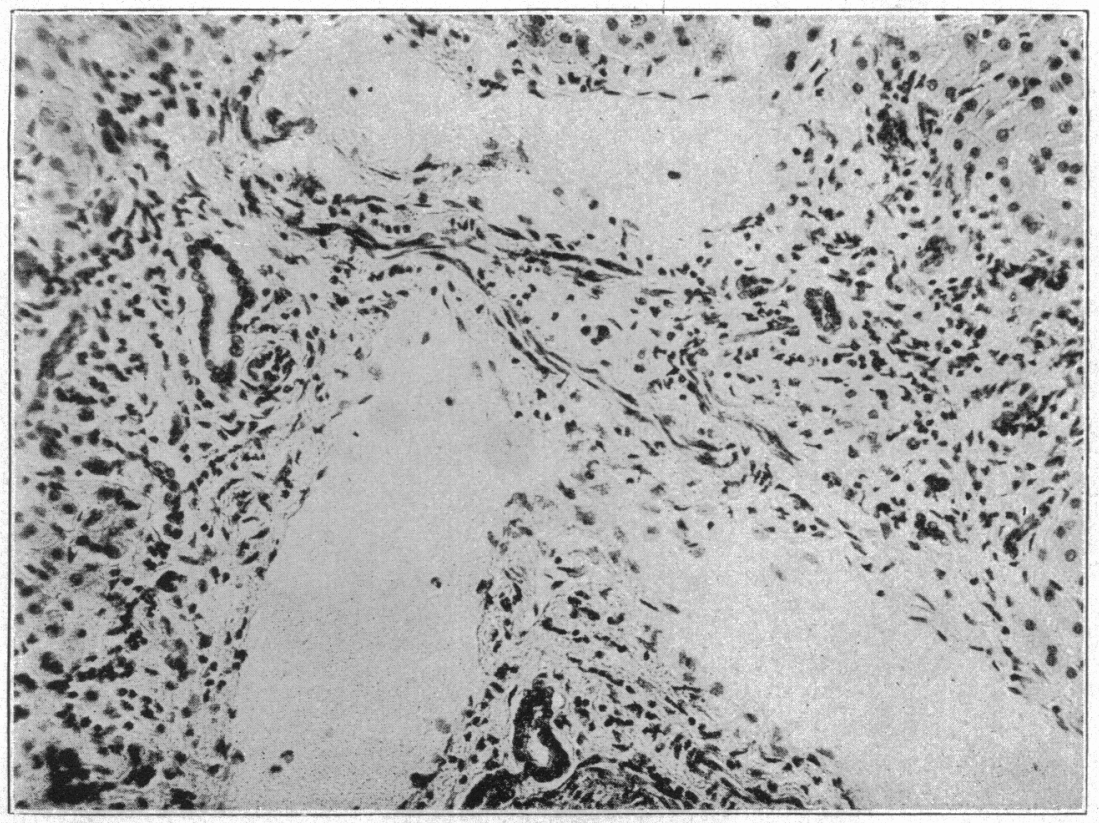

Fig. 2.-Recent productive hepatitis with productive Jymphangitis around the vessels. Zeiss: Objective $16 \mathrm{~mm}$. Ocular $12 \mathrm{~mm}$.

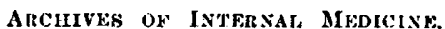

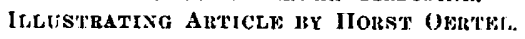


and progressively; it degenerates and wastes, and favorable conditions for the production of a cirrhosis are given. Then, as fibroblastic proliferation progresses from outside, and their own endothelial proliferation from the inside, the interference with these functions becomes greater and greater, and as a result the injury to the parenchyma increases correspondingly. While an attempt is made to counteract this by the formation of new lymph channels, along with newly-formed capillaries, this is in all probability not sufficient, and in the majority of cases these newly-formed lymphaties are not even permanent, but are lost by the slow but constantly progressing inflammatory production of new tissue.

To recapitulate: Inflammatory conditions of the liver are associated with an exudative lymphangitis and perilymphangitis. If, in the subsidence of the infiammatory irritation, the lymphatics are cleared and nothing stands in the way of resorption of inflammatory irritants and products, a change to the normal may take place. If, on the other hand, the lymphatics are not cleared, they form an essential factor in the establishment of a progressing inflammation in the form of an exudative and productive or pure "cirrhosis" of the liver.

Tiewed in this light, some forms of cirrhosis of the liver appear primarily only as an inflammation of the portal spaces, which, on account of unfavorable conditions, particularly for resorption, and a consequent interference with nutrition, lead to degeneration and loss of parenchyma. This is necessarily followed by a fibroblastic proliferation which replaces wasted areas. Maturing in the more slowly progressing forms, this inflammation is apt to undergo frequent exudative exacerbations. These will involve the lymphatics in exactly the same fashion as in a previously normal liver, and they will, therefore, become diffuse and lead to further injury of the parenchyma. In a liver already much changed such acute exacerbations are apt to lead to speedy exitus.

I said before that I believe that some forms of cirrhosis have this pathogenesis, for I do not want to imply that all are the result of such changes. On the contrary, there are undoubtedly forms which commence with marked injury to the parenchyma as well, and in those a hyperplastic proliferation of the connective tissue seems to follow more closely in the path of this primary, parenchymatous destruction. Histologically these two forms present distinctions. The first group includes all those cases in which, especially early in the disease, the parenchyma appears relatively well preserved, and the inflammation and formation of fibrous tissue appear almost out of proportion to the degeneration of the parenchyma. In the second group, however, are all cases in which the 
parenchyma shows, even early, an extensive parenchymatous and fatty degeneration, bile imbibition and various forms of cytolysis. There the inflammatory interstitial changes are irregular, not so distinctly periinsular, but diffuse, plainly intralobular, and this diffuse infiltration which allows free invasion of inflammatory products is made possible by primary, severe involvement of the liver cells themselves. In this connection I should draw attention to the fact that the classification of the various forms of cirrhosis of the liver, which has been especially attempted by the French and to a large extent followed in this country, appears perfectly impossible from an anatomical standpoint, for these forms appear of such close relation, and merge so freely into one another, that it seems unjustifiable to attempt to hold the cirrhoses too rigidly into definite classes. We should rather view them as of a uniform nature modified only by the number and quality of surrounding conditions in each case.

One great mistake which has frequently been made, even by pathologic anatomists, the distinction of two great groups of cirrhoses, namely, the so-called interlobular and intralobular forms, is certainly based on false interpretation. As a matter of fact, all forms of cirrhosis are intralobular, for there is no cirrhosis, not even the old typical Laennec's cirrhosis, which is not intralobular. The pictures in this form of cirrhosis which have been wrongly interpreted as being the result of a distinctly interlobular formation of fibrous tissue to not in reality present such a process. They are produced only by the slow advance of bands of mature fibrous tissue into the liver parenchyma whereby groups of liver cells are cut off from their surroundings and appear in the form of islands, which have been wrongly interpreted by some writers as representing always individual lobules or groups of lobules. More correctly, these islands are frequently produced by cutting off various portions of a number of acini by a distinctly intraacinar growth of fibrous connective tissue. The distinction between this form of cirrhosis, then, and the so-called intralobular form lies not in a characteristic typical distribution of connective tissue, for in both of them this is an intralobular growth; it depends rather on the surrounding conditions of each case, which in the one limit its growth by better parenchymatous preservation, while in the other the growth is diffuse from the start on account of the greater injury to the parenchyma. Whatever other features may become associated with any case, they are not characteristic of particular groups of cirrhotic processes, but are determined by the accompanying conditions of each 
case. These are mainly angiocholitis, bile duct formation, and lesions leading to stasis and ascites.

The terms interlobular and intralobular, as distinctive features of types of cirrhosis, are, therefore, false, and for descriptive purpose the terms periinsular and diffuse would be decidedly preferable. Undoubtedly combinations of the two classes are not infrequent, and this is especially well shown in cases of old periinsular cirrhosis which undergo cxudative exacerbation. Here observation proves, in addition to the old mature periinsular cirrhosis, the recent more diffuse spread of inflammatory products. This may be interpreted as being due to the result of the previous interstitial inflammation, as I outlined it above, which has injured the remaining cells sufficiently to allow a free entrance of the inflammation into the remaining islands whenever an exudative exacerbation occurs. All "acute" exacerbations, then, of chronic cirrhosis lead to the so-called "mixed forms," that is, to a very diffuse distribution of the newly-formed fibrons tissue, which must, necessarily, be associated with more complicating secondary results than the limited old form upon which it was implanted.

In the discussion of the pathogenesis of cirrhosis of the liver we have, as is well known, two opposing views. Some regard it as a primary inflammatory interstitial growth and consider that the loss of parenchyma is dependent upon it. Others, however, deny the possibility of this extensive connective tissue proliferation without previous injury and waste of parenchyma, and believe the fibrous tissue growth to be an entirely compensatory process.

I am inclined to take a stand somewhat between these two, and more or less reconciling them, inasmuch as I believe that the origin of the true cirrhosis of the liver must be looked for in the interstitial inflammation; and that either this may be associated from the start with a severe injury to the parenchyma, which involves diffuse, irregular, fibrous tissue growth throughout the liver, or the parenchyma may become involved much more gradually and largely secondarily on account of the previously outlined progressive features of this interstitial inflammation. In such instances the parenchyma wastes more slowly, as a consequence of which the connective tissue grows in a more or less periinsular fashion. While, then, the origin of the cirrhosis is primarily an interstitial inflammation, the cirrhotic process proper is eminently a compensatory process which depends upon extensive or more slowly progressing, irregular destruction of the parenchyma. A combination of the two types is possible and not at all infrequent. 
I can not leave this subject without a few remarks about the so-called hypertrophic cirrhosis, or Hanot's type. A proper discussion of this lesion, which, as some insist, is a distinct anatomic and clinical entity, is made extremely difficult by the conflicting testimony of its own adrocates. The characteriatic features of this so-called entity have been rariously described, either more grossly as hypertrophy or, better, as enlargement of the liver with a smooth surface and jaundice, a large spleen and no ascites, or, microscopically, as an exclusively intralobular formation of thin connective tissue fibrils between individual liver cells around the bile ducts, with cholangitis and new bile-duct formation, and finally preservation of liver cells. Some would regard one or the other, or several of these, as the distinguishing features, and dispute the others, and few agree even with Hanot himself about the character of the process. This disagreement of authors has gone so far that a few now proclaim that the intralobular formation of delicate fibrous connective tissue, which is by every one practically admitted to occur in this disease, was not a feature of the original findings of Hanot.

Cases of cirrhoses with more or less smooth enlargement of the organ were observed from time to time before Hanot, and Hanot himself has drawn attention to these in sercral of his writings on the subject. Notable among them is the one by Hayem, ${ }^{3}$ 18r4. But it was Hanot who primarily insisted on the establishment of a special type on the basis of some cases which he had collected and presented in 1876. He founded his description on a number of partly anatomic and partly clinical peculiarities, which, in order to aroid confusion, I will quote in his own rrords found on page 89 from the original publication :

It is, therefore, clear that Hanot recognized from the start an intralobular as well as an interlobular connective tissue growth without contraction, and also a catarrhal condition of the bile ducts with their abnormal development. His clinical characteristics need not detain us here, but it is interesting to know that he distinctly contrasted the pathogenesis of atrophic and hypertrophic cirrhosis, inasmuch as he was led to believe

3. Hayem: Contribution a l'etule de l'hepatite interstitielle chronique avec hypertrophie (sclérose ou cirrhose hỵpertrophique du foie). Arch. de physiol., $18 \bar{i}$, i.

4. Hanot, V: Etude sur une forme de eirrhose hypertrophique du foie (cirrhose hypertrophique arec ictere chronique), Paris, 1876.

Parmi les différentes lésions du foie qui ont été englobées sous la dénomination de cirrhose hypertrophique, il en est une qui est rraiment spéciale, et qui se compose des éléments suivants: sclêrose extra-lobulaire trés-accusée et sans tendance a la rêtraction du tissu conjunetị de nouvelle formation; souvent aussi sclérose intro-lobulaire; developpement anormal et catharre chronique des canalicules biliaires. 


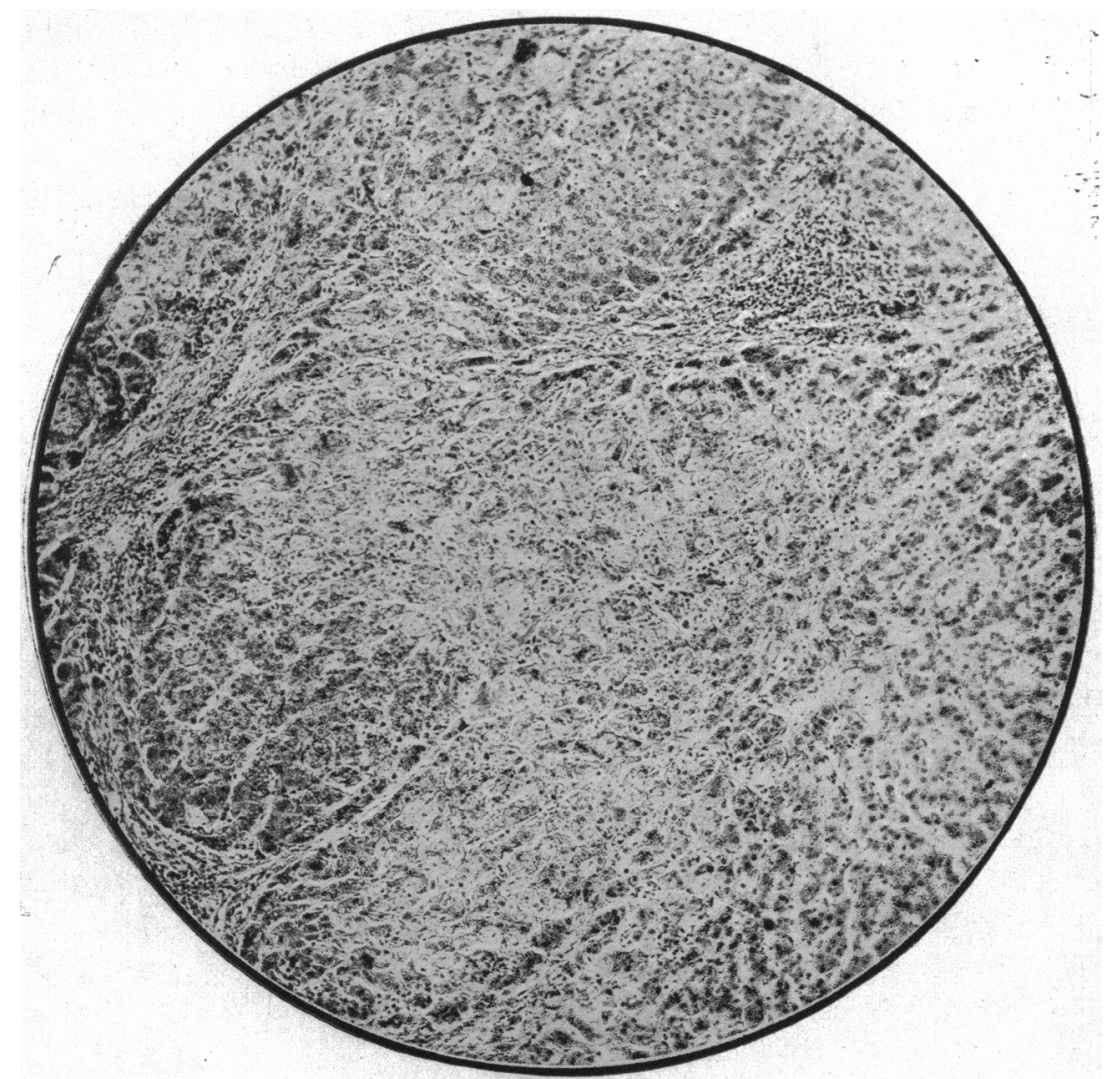

Fig. 3.-Perinsular and diffuse sclerosis; exulative and productive hepatitis. from a large but distinctly granular and much jamuliced liver. It show a variety of lesions: In the center the type is that described ly kretz; at the periphery more a simple perinsular sclerosis. J3ile-dnet formation and angio cholitis moderate and irregular. Zeiss: Objective 16 mm., oenlar $6 \mathrm{~mm}$. The photographs are by Mr. A. J. Martin, artist to the livesel? Sage Institute.

Archives of Intrieval, Mrotcine.

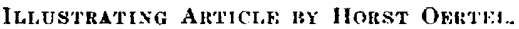

Downloaded From: http://archinte.jamanetwork.com/ by a West Virginia University Library User on 06/21/2015 
that the atrophic cirrhosis took its origin around the radicles of the portal vein, while it was characteristic of the hypertrophic cirrhosis with icterus that it took origin from the bile canaliculæ. In his later monograph on the subject ${ }^{5}$ he also emphasizes the good preservation of the liver cells.

In the subsequent discussion of the disease, however, all of these various features which Hanot advanced then, and later in modified form, have been put forward as characteristic by its supporters, notably in order to save the disease from being disregarded as an entity. At present there are a number of different conceptions which are more or less removed from Hanot's ideas, but which still go under the name of Hanot's cirrhosis, all the distinguishing features which were originally and subsequently claimed for this discase having gradually been denied, differently interpreted or found in other forms of cirrhosis.

Hanot, as we have seen, speaks of an interlobular and intralobular cirrhosis, but he himself attached much greater significance to the bile ducts and the origin of the disease from them than to the cirrhotic lesion itself. Subzequent investigators, however, have paid more attention to the distribution of the connective tissue, and have even gone so far as to disregard the involvement of the bile ducts or the origin of the lesion from them, which was particularly emphasized by Hanot. This is especially true of some of the German writers who have accepted the division of cirrhosis into the atrophic and hypertrophic forms. Kaufman, ${ }^{6}$ for example, claims as characteristic of Hanot's cirrhosis an extremely fine, diffuse intraacinar connective tissue proliferation, and distinguishes it distinctly from biliary cirrhosis. He further differs from Hanot in stating that the liver cells, that are definitely involved, contain fat and bile pigment, become atrophic and disintegrate with the formation of clumps of bile. He refutes the idea of good preservation of liver cells in hypertrophic cirrhosis as a false interpretation of attempts at regeneration, the latter having been demonstrated through the finding of karyokinetic figures by Prus. Very similar are the ideas, with regard to hypertrophic cirrhosis, which are held by Kretz, ${ }^{7}$ who presented two livers before the German Pathological Society in 1905, which he considered typical of Hanot's disease. 'These cases were characterized by a diffuse intralobular formation of fibrous tissue with considerable atrophy of liver cells, vacuolization, and fatty infiltration, but without capillary

5. Hanot, V: La cirrhose hypertrophique avec ictére chronique, Paris, 1892.

6. Kaufman, E: Jehrbuch der speziellen pathologischen Anatomie, 1907.

7. Kretz, R.: Ueber die Abgrenzung der Hanotischen Krankeit gegen die Lebercirrhose mit Ikterus. Verhandlungen der deutschen pathologischen Gesellschaft, 1905 . 
cholangitis, bile imbibition, or bile thrombi. He, therefore, claims as the distinguishing feature of Hanot's cirrhosis, diffuse intralobular connective tissue growth without capillary cholangitis. It is perfectly clear from the foregoing that, while Kretz speaks of these as Hanot's cirrhosis, this cirrhotic process has not much in common with the ideas which were advanced by Hanot, since the latter paid particular attention to the inrolvement of the bile ducts and the good preservation of the liver cells. While, then, some of the Germans consider that Hanot's cirrhosis consists of diffuse smooth enlargement of the liver with considerable bile imbibition but no capillary cholangitis, and with a destruction of the liver cells, others follow Charcot and proclaim this a special feature. Rolleston $^{8}$ has retained more or less the original typical Hanot description and groups it as biliary hypertrophic cirrhosis.

On the other hand, some pathologie anatomists refuse to recognize any of these features as sufficiently characteristic evidence to permit of the establishment of a definite classification, and with these I must agree. In the first place it has been held that it is characteristic of the so-called lypertrophic cirrhosis to show a lack of contraction due to an even distribution of the cirrhosis, but that this may be found in other rarieties of cirrhosis has long been well known. In fact Orth, in his text-book of special pathologic anatomy, ${ }^{9}$ describes distinctly cases of smooth atrophic cirrhosis which are due to a very fine uniform distribution of the connective tissue. We have in our collection in this institute a perfect example of such a cirrhosis, which presents a smooth surface as the result of very general and even connective tissue growth which goes hand in hand with a corresponding loss of hepatic substance. On the other hand, there occur cases of cirrhosis with jaundice and marked enlargement of the organ which are distinctly granular as a whole, or in places. How are these to be regarded? The integrity of the liver cells which has been proclaimed as distinctive by some writers can not be held to be in any way characteristic. That feature is open to too much rariation, and in every cirrhosis, especially in the typical atrophic forms, one will run across many areas of parenchyma which appear well preserved, to say nothing of the attempts at regeneration which have been shown by Prus. Again, in the forms with marked enlargement and jaundice the parenchyma may be diffusely and severely altered.

With regard to the distribution of the cirrhotic tissue itself, I have already stated that all cirrhoses are intralobular as well as interlobular,

8. Rolleston, H. D.: Disease of the Liver, 1905.

9. Orth, J.: Lehrbuch der speziellen pathologischen Anatomie, 1887, i. 
and that a periinsular cirrhosis may at any time become a diffuse intralobular form, if in the course of exacerbations the remaining islands should become injured to such an extent as to allow of an invasion of connective tissue in the form of denser or fine fibrillar bands into them. Finally, the presence of cholangitis and bile duct formation can certainly not be characteristic, for these occur in a number of cases of ordinary cirrhosis, and, as the observations of Kretz show, they may even be absent in cases which otherwise entirely resemble Hanot's cirrhosis. It will, therefore, be seen that the conditions which may be associated with smooth or granular enlargement of the liver and with jaundice are variable and depend upon even more different conditions than were found by the originator of the term. The absence or presence of accessory conditions, like jaundice, ascites and splenic enlargement, can certainly not be utilized in the classification of the cirrhotic lesion, for they depend, as I have outlined above, upon a number of extremely rariable pathological lesions which are partly the result of the cirrhotic process itself, and partly of superadded, concomitant, and more or less independent lesions.

At this present stage of our knowledge it seems unjustifiable to insist on the establishment of definite classes of cirrhoses of the liver. We have to deal here with variations which allow such frequent combinations that even clinically we can not gain much by attempting to do this (Fig. 3).

At the symposium on neplritis before the German Pathological Society in 1905 Orth made this remark at the end of the excellent presentations of Ponfick and Fr. Müller on the subject:

Die Lehre von der Nephritis enthält so viele Einzelfragen, dass wir tagelang diskutieren könnten, wenn wir sie alle eigehend behandeln wollten, ich werde mich deshalb nur auf einige kwze Bemerkungen beschänken. Es ist vorher die Hoffnung ausgesprochen worden, dass man heute festere Grundlagen für die Nomenklatur und Systematik der Nierenkranklieiten gewinnen wäde, ich glaube nicht der einzige zu sein, welcher das Gefuihl einer Enttäuschung empfunden hat, denn wenn man das Resultat von Referat und Korreferat ibersieht, so muss man doch sagen, das dasselle nur ist, dass wir noch fast nichts wissen.

The same sentiments I voice to-day in another subject after a review of our knowledge and some independent study of the inflammations of the liver. Those who believe that morphological investigation of diseases of organs has reached its final results should appreciate that we have really just begun to correlate our morphological experience and develop the variations in its relations. In the future, as in the past, no proper idea of a disease will exist without knowledge of these relations, and both the pathologist and the clinician of to-day should appreciate that proper conception of a disease can stand only on this basis. In the gradual evo- 
lution of pathological conceptions a great many previously established sharp lines of demarcation are wiped away, just as they gradually disappeared in zoology after the appreciation of the theory of evolution.

Guided by these considerations, I now use the following very broad classification for diffuse inflammations of the liver, which, although it does not draw rigid lines, allows of the combination of variations which are much closer to the actual anatomical finding.

I have discarded entirely the terms acute, subacute and chronic, which have no place in anatomic terminology, and have substituted descriptive terms which allow proper anatomical conceptions.

1. I speak of degenerative exudative hepatitis, now called acute hepatitis, in cases which are characterized in varying degrees and in varying combinations by cellular exudation taking origin from the portal spaces, by lymphangitis, perilymphangitis and cholangitis, by diffuse parenchymatous and fatty degenerations of the liver cells, and by cytolysis and bile imbibition.

2. I speak of degenerative productive hepatitis in cases which are now grouped as subacute hepatitis, and divide them into two forms: the first with a more rapid loss of substance, grossly appears more or less granular, the second with a much more gradual loss of substance has consequently a more uniform, even distribution of connective tissue and is, therefore, smooth. Both of these may be associated with either enlargement or diminution in size of the liver. They are characterized, microscopically, by a productive cellular inflammation proceeding from the portal spaces, which is periinsular and diffuse: a productive lymphangitis and a productive pericholangitis. It is further characterized in varying degree, and more or less accentuated by, more slowly progressing, irregular, parenchymatous and fatty degenerations and fatty infiltration, cytolysis, bile imbition, and the formation of new, mature and embryonic Jiver cells (bile ducts).

3. I speak of productive hepatitis, for which I also use the term sclerosis of the liver (which is to be preferred to cirrhosis of the liver), and this is characterized essentially by the formation of mature, periinsular, or diffuse connective tissue formation; depending upon the loss of liver substance and the distribution of connective tissue, it is either granular or smooth and goes along with enlargement or diminution in size of the organ. It further presents very slowly progressing, irregular, parenchymatous and fatty degenerations, and fatty infiltration, cystolysis, little or moderate bile imbibition, and the formation of mature and embryonic liver cells (bile ducts).

30 West Forty-fourth street. 